Available online:

http://journal.imla.or.id/index.php/arabi

IMLA

Arabi : Journal of Arabic Studies, 2 (2), 2017, 156-162

DOI: http://dx.doi.org/10.24865/ajas.v2i2.56

\title{
PEMANFAATAN MEDIA PEMBELAJARAN GAME INTERAKTIF DALAM PEMBELAJARAN KOSAKATA BAHASA ARAB
}

\author{
Muhammad Luqman Hakim, Akhyar, Asrowi \\ Universitas Sebelas Maret, Surakarta, Indonesia \\ E-mail : manluq47@gmail.com
}

\begin{abstract}
Arabic language is one of the areas of study taught at the level of junior high school. Learning of Arabic language on the this level directed at the fourth skill, there are; listening skills (mahärah al-Istimä), speaking skills (mahārah al-Kalām, reading skills (mahärah al-Qirä'ah), and writing skills (mahārah al-Kitābah).The fourth skill cannot be achieved without having a good mastery of vocabulary, because the quality of a person's language skills depends on the quantity and quality of its own vocabulary. This research aims to obtain information about the needs of the media in learning Arabic language. The method used is qualitative descriptive and review of the literature. The results of this research is in the Arabic language learning requires media interactive games to make learning interesting and can facilitate the learning process.
\end{abstract}

Keywords: vocabulary mastery, Arabic learning, interactive games

\begin{abstract}
Abstrak
Bahasa Arab merupakan salah satu bidang studi yang diajarkan pada tingkat Sekolah Menengah Pertama atau sederajat. Pembelajaran bahasa arab pada tingkat tersebut diarahkan pada penguasaan keempat keterampilan berbahasa (Mahärah al-Arba') yang meliputi keterampilan mendengar (mahärah al-Istimā'), keterampilan berbicara (mahārah al-Kalām), keterampilan membaca (mahārah al-Qiräăah) serta keterampilan menulis (mahärah al-Kitābah). Keempat keterampilan tersebut tidak bisa dicapai tanpa memiliki penguasaan kosakata yang baik, karena kualitas keterampilan berbahasa seseorang bergantung kepada kuantitas dan kualitas kosakata yang dimilikinya. Penelitian ini bertujuan untuk memperoleh informasi tentang kebutuhan media pembelajaran dalam pembelajaran bahasa Arab. Metode yang digunakan kualitatif deskriptif dan telaah pustaka. Hasil dari penelitian ini ialah dalam pembelajaran bahasa Arab sangat membutuhkan media pembelajaran game interaktif agar pembelajaran menarik dan dapat mempermudah proses pembelajaran.
\end{abstract}

Kata Kunci: penguasaan kosakata, kebutuhan, game interaktif 


\section{Pendahuluan}

Manusia sejak lahir berusaha untuk dapat berkomunikasi dengan lingkungannya. Karena itu, lahirlah bahasa masyarakat tertentu tanpa harus musyawarah terlebih dahulu. Karena setiap masyarakat melahirkan bahasa untuk berkomunikasi di kalangan mereka, maka terjadilah bahasabahasa yang beraneka ragam sesuai dengan keadaan masyarakat tertentu.

Bahasa adalah sistem bunyi yang bersifat arbitrer yang digunakan sekelompok orang sebagai sarana untuk menyampaikan pikiran dan perasaan mereka. Bahasa merupakan kumpulan bunyibunyi yang tersusun secara teratur sehingga menimbulkan makna, diujarkan secara lisan, dan digunakan untuk mengungkapkan pikiran manusia (Mulyati, 2008: 2-3).

Bahasa juga merupakan alat komunikasi yang utama, kreatif, dan cepat bagi manusia untuk menyampaikan ide, pikiran dan perasaannya. Bahasa tidak mungkin terpisahkan dari kehidupan manusia, karena manusialah yang menggunakan bahasa itu sendiri untuk berinteraksi.

Sebagai salah satu bahasa internasional yang telah menjadi bahasa resmi PBB sejak 1973, disamping bahasa Inggris, bahasa Perancis, bahasa Spanyol, bahasa Rusia, dan bahasa Cina, bahasa Arab telah menjadi bahasa resmi bagi 21 negara di Asia bagian Barat dan Afrika bagian Utara, dari Irak di Timur sampai Maroko di Bagian Barat. Ditambah lagi bahawa bahara Arab telah menjadi bahasa resmi dalam organisasi lainnya seperti Liga Arab, Konferensi Islam, dan Persatuan Afrika.

Melihat pentingnya bahasa Arab pada ranah bahasa Indonesia, Moeliono (1989: 119) menyatakan bahwa bahasa Arab adalah bahasa dengan tujuan khusus, karena banyaknya kata dan ungkapan yang berasal dari bahasa ini masuk dalam kosa kata bahasa Indonesia, khususnya dalam masalah peribadatan.

Berdasarkan peraturan Menteri Agama Republik Indonesia Nomor 2 Tahun 2008 mata pelajaran Bahasa Arab merupakan suatu mata pelajaran yang diarahkan untuk mendorong, membimbing, mengembangkan, dan membina kemampuan serta menumbuhkan sikap positif terhadap bahasa Arab baik represif maupun produktif. Kemampuan represif yaitu kemampuan unntuk memahami pembicaraan orang lain dan memahami bacaan. Kemampuan produktif yaitu kemampuan menggunakan bahasa sebagai alat komunikasi baik secar lisan maupun tulis.

Bahasa Arab merupakan salah satu bidang studi yang diajarkan pada tingkat Sekolah Menengah Pertama atau sederajat (MTs) atau sederjat. Pembelajaran bahasa arab pada tingkat tersebut diarahkan pada penguasaan keempat keterampilan berbahasa (mahārah al-Arba') yang meliputi keterampilan mendengar (mahārah al-Istimā'), keterampilan berbicara (mahārah alKalām), keterampilan membaca (mahārah al-Qirā'ah) serta keterampilan menulis (mahārah alKitābah).

Kualitas keterampilan berbahasa seseorang bergantung kepada kuantitas dan kualitas kosakata yang dimilikinya. Semakin kaya kosakata yang kita miliki, semakin besar pula kemungkinan kita terampil berbahasa. Baik tidaknya nilai rapor itu mencerminkan baik atau tidaknya keterampilan keberbahasaan mereka, naik atau tidaknya kuantitas dan kualitas kosakata mereka. Apabila masalah ini dipahami benar-benar maka dapatlah dimengerti betapa pentingnya pengajaran kosakata yang bersistem di sekolah-sekolah sedini mungkin. Kuantitas dan kualitas kosakata seorang siswa turut menentukan keberhasilannya dalam kehidupan (Tarigan, 2011: 2).

David Wilkins, dikutip Thornbury (2002: 13), menyimpulkan tentang pentingnya mempelajari kosakata dengan mengatakan "Without Grammar very little can be conveyed, without vocabulary nothing can be conveyed." Ia menjelaskan bahwa tanpa (mengetahui) grammar, sedikit sekali yang bisa kita ungkapkan. Namun tanpa (mengetahui) kosakata, tidak ada yang bisa kita ungkapkan. Memang benar apa yang diungkapkan oleh Wilkins tersebut. Meski kita mempunyai kemampuan grammar (tata bahasa) yang baik, namun kemampuan tersebut akan siasia saja jika kita tidak memiliki cukup penguasaan akan kosakata.

Bahasa Arab telah lama berkembang di Indonesia, akan tetapi tampaknya mempelajari bahasa Arab sampai sekarang tidak terlepas dari problematika. Salah satunya diantaranya adalah problem dalam hal menggunakan metode pada saat proses pembelajaran bahasa Arab berlangsung. 


\section{Arabi : Journal of Arabic Studies}

Selain itu tenaga pengajar (guru) di Indonesia sedikit sekali yang menguasai pelajaran bahasa Arab. Mereka menegajar bahasa Arab dengan menggunakan pengantar Indonesia. Metode yang mereka gunakan adalah metode mengajar di mana mereka mendapatkan pelajaran dari gurunya dulu yang pada umumnya menggunakan metode gramatika dan terjemah (thariqah al-qawä'id wa at-tarjamah). (Mu'in, 2015: 41)

Fakta di lapangan, pembelajaran bahasa Arab masih menggunakan metode gramatika dan terjemah (thariqah al-qawā'id wa at-tarjamah). Peneliti juga mendistribusikan tes kepada 27 siswa tentang penguasaan kosakata bahasa Arab, hasilnya 25\% dari siswa memiliki nilai ketuntasan yang baik, namun $75 \%$ belum dikatakan tuntas. Hal ini begitu memprihatinkan mengingat sekolah bersistem boarding school memiliki kelebihan dalam mengontrol siswanya untuk memiliki keterampilan bahasa Arab.

Dalam pembalajaran bahasa Arab diawali dengan pemberian atau pembelajaran kosakata bahasa Arab. Hal yang demikian memiliki tujuan. Tujuan pembelajaran kosakata (mufradāt) bahasa Arab adalah sebagai berikut: a) Memperkenalkan kosakata baru kepada siswa, baik melalui bacaan maupun fahm al-masmü'. b) Melatih siswa untuk dapat melafalkan kosakata itu dengan baik dan benar, karena pelafalan yang baik dan benar mengantarkan kepada kemahiran berbicara dan membaca secara baik dan benar. c) Memahami makna kosakata, baik secara denotasi atau leksikal maupun ketika digunakan dalam konteks kalimat tertentu. d) Mampu mengapresiasi dan memfungsikan mufradāt itu dalam berekspresi lisan maupun tulisan sesuai dengan konteksnya. (Mustafa, 2011: 63)

Bahasa Arab merupakan salah satu mata pelajaran yang membutuhkan kemampuan guru dalam mengelola kelas. Terutama, kemampuan guru dalam memanfaatkan media yang bisa menciptakan suasana nyamaman dan menyenangkan sehingga dapat menarik minat dan mengaktifkan siswa untuk mengikuti pelajaran, baik secara mandiri maupun kelompok. Pembelajaran bahasa Arab yang memanfaatkan media menjadi lebih menarik dan dapat mempermudah proses pembelajaran. (Mujib dan Rahmawati, 2013: 63)

Berdasarkan pentingnya bahasa Arab, pembelajaran bahasa Arab sesungguhnya sangat menghendaki keterlibatan siswa secara langsung. Oleh karena itu, hendaknya diterapkan medel pembelajaran interaktif yakni model pembelajaran yang melibatkan siswa secara aktif dan pasif dalam hal ini posisi peserta didik dalam pembelajaran sebagai subjek dan objek pendidikan. Model pembelajaran interaktif ini dimaksudkan untuk memperkenalkan kepada peserta didik mengenai sejumlah pengetahuan materi-materi tertentu yang sudah diajarkan kepada mereka, sekaligus menghadapakan peserta didik pada sejumlah masalah untuk dipecahkan secara bersama-sama. (Wa Muna, 2011: 19)

Berdasarkan pentingnya penguasaan kosakata dan fakta di lapangan, peneliti ingin mendiskirpsikan informasi tentang kebutuhan media pembelajaran dalam pembelajaran bahasa Arab.

\section{Penguasaan Kosakata}

Kosakata dalam bahasa Arab atau yang disebut dengan mufradat, merupakan himpunan kata-kata atau khazanah kata yang diketahui oleh seseorang atau etinitas lain yang merupakan bagian dari bahasa tertentu. Dalam bahasa inggris kosakata disebut dengan vocabulary. Kosakata juga dapat diartikan sebagai himpunan kata-kata yang dimengerti oleh orang tersebut dan kemungkinan akan digunakannya untuk menyusun kalimat baru. Kosakata merupakan salah satu dari tiga unsur bahasa yang harus dikuasai, kosakata ini digunakan dalam bahasa tulis maupun bahasa lisan, dan merupakan salah satu alat untuk mengembangkan kemampuan berbahasa Arab seseorang. (Mustafa, 2011: 61)

Menurut Al-khauli dan Mahmud Ali dalam Mustafa (2011: 62) kosakata merupakan kumpulan kata-kata tertentu yang akan membentuk bahasa. Kata adalah bagian terkecil dari 
bahasa yang sifatnya bebas. Dalam kamus online al-Ma'āny, mufradāt memiliki makna seluruh kata-kata yang terdapat di dalam bahasa Arab.

Untuk mengetahui penguasaan kosakata siswa perlu diadakan tes. Tes dalam pembelajaran kosakata dapat dikelompokkan menjadi tes pemahaman dan tes penggunaan. (M.Ainin, dkk, 2006: 132) Tes pemahaman lebih ditekankan pada pengukuran kemampuan siswa dalam memahami arti kosakata, sedangkan tes penggunaan lebih dititikberatkan pada kemampuan siswa menggunakan kosakata dalam suatu kalimat. Khusus untuk tes pemahaman kosakata, indikator kompetensi yang diukur dapat berupa arti kosakata, padanan kata, antonim kata, sinonim kata, pengertian kata, dan kelompok kata.

\section{Pemanfaatan Media Game Interaktif}

Smaldino (2008: 6) mengatakan bahwa media bentuk jamak dari perantara (medium), merupakan sarana komunikasi. Berasal dari bahasa Latin medium (antara), istilah ini merujuk pada apa saja yang membawa informasi antara sebuah seumber dan sebuha penerima.

Menurut Retno (2011: 1) dalam Dony Novaliendry menyatakan bahwa "Game berasal dari kata bahasa Inggris yang memiliki arti dasar permainan. Permainan dalam hal ini merujuk pada pengertian kelincahan intelektual (intellectual playability)". Game juga bisa diartikan sebagai arena keputusan dan aksi pemainnya, ada target yang ingin dicapai pemainnya. Kelincahan intelektual pada tingkat tertentu merupakan ukuran sejauh mana game itu menarik untuk dimainkan secara maksimal. Game juga secara nyata mempertajam daya analisis para penggunanya untuk mengolah informasi dan mengambil keputusan cepat yang jitu.

Asnawir dan Usman (2002: 24) memberi penjelasan bahwa penggunaan media pembelajaran dapat menarik perhatian siswa lebih besar kegiatan pembelajaran dapat berjalan lebih menyenangkan dan tidak membosankan, serta lebih menarik perhatian dan minat siswa dalam belajar.

Selain itu media pembelajaran dapat menarik perhatian siswa sehingga dapat menumbuhkan motivasis belajar, serta siswa lebih banyak melakukan kegiatan belajar, sebab tidak hanya mendengarkan uraian guru, tetapi juga aktivitas lain seperti; pengamatan, melakukan, mendemostrasikan dan lain-lain. (Sudjana dan Rivai, 1991: 3)

\section{Metode}

Pendekatan yang digunakan dalam penelitian ini adalah pendekatan kualitatif dan studi pustaka. Pendekatan kualitatif dipilih karena penelitian ini menggunakan interaksi sosial sebagai cara memperoleh data dari sumber data secara alami. Sumber data penelitian ini tes penguasaan kosakata, observasi, dan wawancara pada guru mata pelajaran bahasa Arab SMP IT Al Huda.

Studi Pustaka, merupakan metode pengumpulan data dengan cara mencari, membaca dan mempelajari buku-buku literatur, jurnal, dan internet yang berhubungan dengan judul penulis mengambil sebagai bahan pembanding atau dasar pembahasan lebih lanjut serta untuk memperoleh landasan-landasan teori dari sistem yang akan dikembangkan sehingga penulisan dan penyusunan karya ilmiah ini tidak menyimpang dari teori - teori yang sebelumnya telah ada dan diakui kebenarannya.

Data penelitian ini bersifat deskriptif, artinya kosakata yang menjadi data utama penelitian ini adalah sumber deskripsi yang memaparkan mengenai seluk-beluk penguasaan kosakata bahasa Arab. Oleh karena itu, metode yang digunakan dalam penelitian ini adalah metode penelitian deskriptif kualitatif. Metode penelitian deskriptif kualitatif dipandang sesuai untuk mendeskripsikan secara sistematis, faktual, dan akurat mengenai penguasaan kosakata bahasa Arab. 


\section{Arabi : Journal of Arabic Studies}

\section{Hasil Penelitian}

Sebagai sekolah yang bersistem asrama, rasanya bukan hal yang tidak mungkin menerapkan pembelajaran bahasa Arab. SMP IT Al-Huda telah berupaya semaksimal mungkin untuk menerapkan pembelajaran bahasa Arab. Pembelajaran yang diterapkan di SMP IT Al Huda di kelas-kelas menggunakan metode gramatika terjemah (Qawā'id wa Tarjamah). Sebenarnya tidak salah jika metode gramatika terjemah (Qawā'id wa Tarjamah) dalam pembelajaran bahasa Arab, akan tetapi penerapan pembelajaran dengan menggunakan metode tersebut dinilai belum efektif. Hal ini dapat dicerminkan dari hasil tes penguasaan kosakata.

Kepala Sekolah menyatakan bahwa pembelajaran bahasa Arab belum bisa mempengaruhi keterampilan siswa dalam berbahasa Arab. Pada intinya mereka berpendapat bahwa metode yang diterapkan tidak maksimal untuk menyajikan mata pelajaran bahasa Arab. Disamping itu mereka juga berpendapat kompetensi guru yang mengajar belum memadai.

Data hasil tes, rerata persentase penguasaan kosakata Bahasa Arab siswa yang meliputi kemampuan berupa arti kosakata, padanan kata, antonim kata, sinonim kata, pengertian kata, dan kelompok kata belum berkembang dengan baik dan sesuai harapan akademik dengan persentase rata-rata keseluruhan sebesar 47,9\% dengan uraian sebagai berikut; $A d$ mendapatkan skor 40, $A f$ mendapatkan skor 45, $A g$ mendapatkan skor 20., $A i$ mendapat skor 85, $A j$ mendapatkan skor 25, $A 1$ mendapatkan skor 85, $A m$ mendapatkan skor 50, $A n$ mendapatkan skor 50, Ar mendapatkan skor 35, $\mathrm{Au}$ mendapatkan skor 30, $\mathrm{Az}$ mendapatkan skor 65, $\mathrm{Ci}$ mendapatkan skor 50, $\mathrm{Fa}$ mendapatkan skor 65, Fi mendapatkan skor 30, Ha mendapatkan skor 25, In mendapatkan skor 35, Iy mendapatkan skor 50, Iz mendapatkan skor 55, Ji mendapatkan skor 65 , Ki mendapatkan skor 65, Mi mendapatkan 50, Ni mendapatkan skor 50, Nis mendapatkan skor 30, Ra mendapatkan skor 35, Sa mendapatkan skor 75, $Y u$ mendaptkan skor 60, dan $Z a$ mendapatkan skor 25. Secara lebih jelas dapat digambarkan dalam grafik berikut:

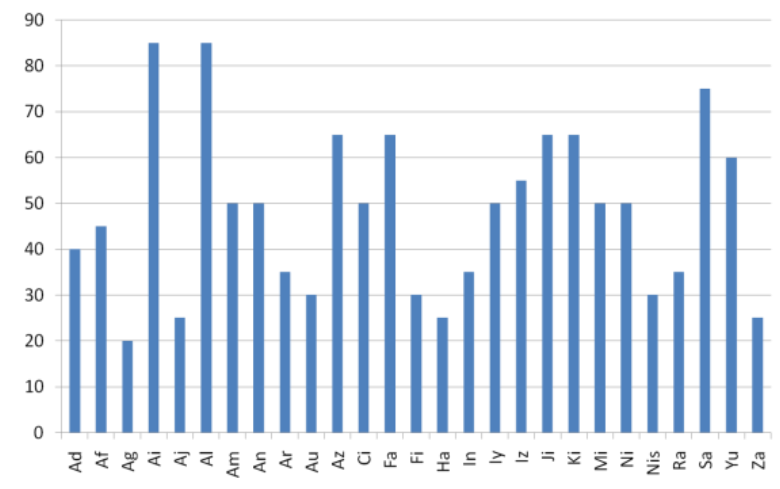

Berdasarkan observasi awal di lapangan, terdapat beberapa temuan yang menjadi beberapa faktor penyebab kurangnya penguasaan kosakata bahasa Arab (mufradät) siswa di sekolah tersebut yakni: faktor pertama, monotonnya guru dalam menggunakan metode pembelajaran (konvensional), guru masih menggunakan metode gramatika dan terjemah (thariqah al-qawä'id wa at-tarjamah), guru mengartikan ke bahasa Indonesia dan siswa cenderung tidak aktif. Faktor kedua, penggunaan media yang kurang variatif, sehingga pembelajaran sering disampaikan secara lisan saja tanpa ada media pendukung yang dapat menarik minat siswa saat guru menjelaskan materi. Faktor ketiga, guru cenderung sebagai pusat pembelajaran (Teacher Centered) dan siswa hanya mendengarkan materi. Faktor keempat, lingkungan yang kurang kondusif dapat mempengaruhi individu keterampilan bahasa Arab, tetapi sebaliknya lingkungan yang kondusif membantu siswa dalam mempraktekkan secara langsung kosakata yang didapatkan.

\section{Pembahasan}

Perlu dikemukakan di sini bahwa pengajaran bahasa bukanlah suatu pekerjaan yang mudah atau lebih rendah dari pekerjaan yang lainnya sebagaimana dibayangkan orang pada umumnya. 
Sebaliknya pengajaran bahasa ialah suatu tugas atau pekerjaan di mana intelegensia, imaginasi, latihan pengetahuan bahasa dan pengalaman serta sejumlah pengetahuan lainnya merupakan komponen-komponen yang sangat berperan bahkan mempunyai nilai yang sangat tinggi. (Rombepajung, 1988: 2)

Dari telaah pustaka, Wa Muna (2011: 19) menyatakan bahwa pembelajaran bahasa Arab sesungguhnya sangat menghendaki keterlibatan siswa secara langsung. Oleh karena itu, hendaknya diterapkan medel pembelajaran interaktif yakni model pembelajaran yang melibatkan siswa secara aktif dan pasif dalam hal ini posisi peserta didik dalam pembelajaran sebagai subjek dan objek pendidikan. Model pembelajaran interaktif ini dimaksudkan untuk memperkenalkan kepada peserta didik mengenai sejumlah pengetahuan materi-materi tertentu yang sudah diajarkan kepada mereka, sekaligus menghadapakan peserta didik pada sejumlah masalah untuk dipecahkan secara bersama-sama.

Pendapat tersebut mengharapkan kepada guru pengajar bahasa untuk menggunakan metode atau media interaktif yang dapat melibatkan siswa secara aktif dalam pembelajaran. Sebenarnya penggunaan metode metode gramatika dan terjemah (tharíqah al-qawä'id wa at-tarjamah) bukan sesuatu yang salah, tetapi jika dilihat dari efektivitas dalam penguasaan kosakata sangatlah kurang.

Bahasa Arab merupakan salah satu mata pelajaran yang membutuhkan kemampuan guru dalam mengelola kelas. Terutama, kemampuan guru dalam memanfaatkan media yang bisa menciptakan suasana nyaman dan menyenangkan sehingga dapat menarik minat dan mengaktifkan siswa untuk mengikuti pelajaran, baik secara mandiri maupun kelompok. Pembelajaran bahasa Arab yang memanfaatkan media menjadi lebih menarik dan dapat mempermudah proses pembelajaran. (Mujib dan Rahmawati, 2013: 63).

Salah satu media interaktif yang hadir pada saat ini ialah game edukasi, game edukasi merupakan permainan yang dikemas untuk merangsang daya pikir termasuk meningkatkan konsentrasi dan memecahkan masalah.

Berdasarkan penelitian yang dilakukan Dwyer (1978), menyebutkan bahwa setelah lebih dari tiga hari pada umumnya manusia dapat mengingat pesan yang disampaikan melalui tulisan sebesar $10 \%$, pesan audio $10 \%$, visual $30 \%$ dan apabila ditambah dengan melakukan, maka akan mencapai $80 \%$.

Penelitian yang dilakukan Woro Kusni tentang "pemanfaatan media permainan scrabble untuk meningkatkanpenguasaan kosakata pada pembelajaran bahasa inggris" menunjukkan bahwa pemanfaatan media permainan Scrabble terbukti berpengaruh positif terhadap peningkatan penguasaan kosakata (vocabulary) pada pembelajaran Bahasa Inggris. Media permainan Scrabble terbukti dapat meningkatkan aktivitas dan motivasi belajar siswa dalam rangka peningkatan penguasaan kosakata (vocabulary) pada pembelajaran Bahasa Inggris.

Begitu juga dengan penelitian yang dilakukan Savitri Arizona mengenai "pengembangan media pembelajaran permainan interaktif kosakata bahasa jepang "moji village" berbasis markerless motion capture untuk meningkatkan kemampuan kosakata kana dan kanji di sma", menunjukkan bahwa terbukti efektif meningkatkan kemampuan kosakata kana dan kanji siswa kelas XII Bahasa SMA Negeri 1 Bangil.

Dari teori dan penelitian yang telah dilakukan oleh peneliti terdahulu, pembelajaran bahasa Arab dengan menggunakan media game interaktif memiliki pengaruh yang positif dalam meningkatkan penguasaan kosakata bahasa Arab.

\section{Simpulan}

Berdasarkan masalah yang dihadapi serta temuan-temuan yang telah dikemukakan dapat dapat disimpulkan bahwa pengajaran bahasa Arab dengan metode gramatika dan terjemah (tharíqah al-qawā'id wa at-tarjamah) belum memberikan hasil yang maksimal. Penguasaan kosakata siswa dipengaruhi beberapa faktor, namun faktor yang dominan yang berpengaruh 


\section{Arabi : Journal of Arabic Studies}

terhadap penguasaan kosakata ialah penggunaan metode gramatika dan terjemah (thariqah alqawā'id wa at-tarjamah) serta lingkungan yang kurang kondusif. Sesungguhnya pembelajaran bahasa Arab menghendaki keterlibatan siswa dalam pembelajaran supaya siswa aktif dan tidak terkesan bosan. Selain itu dibutuhkan kemampuan guru dalam menggunakan media pembelajaran. Oleh karena itu, perlu memanfaatkan media supaya pembelajaran bahasa Arab menjadi lebih menarik dan dapat mempermudah proses pembelajaran. Siswa akan dapat mengingat pesan secara maksimal jika materi yang disampaikan melalui tulisan sebesar $10 \%$, pesan audio $10 \%$, visual $30 \%$ dan apabila ditambah dengan melakukan, maka akan mencapai $80 \%$. Dengan begitu kita dapat memadukan gaya belajar siswa dalam satu media. Media pembelajaran game interaktif diyakini dapat meningkatkan penguasaan Kosakata bahasa Arab. Hal ini didasarkan kepada penelitianpenelitian terdahulu yang menggunakan media game untuk meningkatkan penguasaan kosakata.[]

\section{Daftar Rujukan}

Ainin, Tohir. Asrori, Imam. 2006. Evaluasi Dalam Pembelajaran Bahasa Arab. Malang: Misykat.

Arizona, Savitri. 2014. Pengembangan Media Pembelajaran Permainan Interaktif Kosakata Bahasa Jepang "Moji Village" Berbasis Markerless Motion Capture Untuk Meningkatkan Kemampuan Kosakata Kana Dan Kanji Di SMA. Hikari, Vol 2, No 2.

Asnawir, \& Usman, M.B. 2002. Media Pembelajaran, Jakarta: Ciputat Press.

Dwyer, Francis M. 1978. Strategies for Improving Visual Learning a Handbook for the Effective Selection Design and Use of Visualized Materials. Pennsylvania : Learning Services.

Kusni, Woro. 2014. Pemanfaatan Media Permainan Scrabble untuk Meningkatkan Penguasaan Kosakata Pada Pembelajaran Bahasa Inggris Materi Descriptive Textdi Kelas VIII-A SMP Negeri 5 Ngawi Tahun Pelajaran 2013/2014.

Moeliono, Anton M. 1989. Kembara Bahasa. Jakarta: Gramedia.

Mu'in, Abdullah. 2015. Analisis Kontrastif Bahasa Arab \& Bahasa Indonesia Telaah Fonetik Dan Morfologi. Pekalongan: Duta Media Utama.

Mujib, \& Rahamawati. 2013. Metode Permainan-Permainan Edukatif Dalam Belajar Bahasa Arab. Jogjakarta: Diva Press.

Mulyati, Yeti. 2008. Bahasa Indonesia. Jakarta: Universitas Terbuka

Mustofa, Syaiful. 2011. Strategi Pembelajaran Bahasa Arab Inovatif. Malang: Maliki Press.

Rombepajung. 1988. Pengajaran Dan Pembelajaran Bahasa Asing. Depertemen Pendidikan Dan Kebudayaan.

Smaldino, Lowther, \& Russell. 2008. Instructional Technology And Media For Learning. New Jersey: Pearson.

Sudjana, Nana \& Rivai, Ahmad. 1991. Media Pengajaran. Bandung: Sinar Baru.

Tarigan, Henry Guntur. 2011. Pengajaran Kosakata. Bandung: Angkasa.

Thornbury, Scott. 2002. How to Teach Vocabulary. Pearson Education Limited.

Wa Muna. 2011. Metodologi Pembelajaran Bahasa Arab (Teori Dan Aplikasi). Teras: Yogyakarta. 